
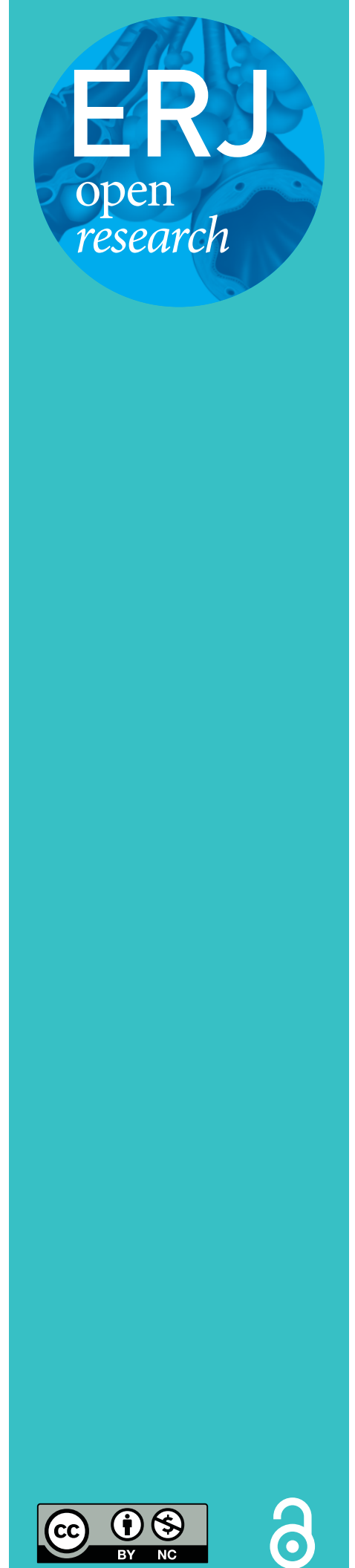

\title{
Cough-provocation tests with hypertonic aerosols
}

\author{
Heikki O. Koskela (10 ${ }^{1,2}$, Hanna M. Nurmi ${ }^{1,2}$ and Minna K. Purokivi ${ }^{1}$
}

Affiliations: ${ }^{1}$ Unit for Medicine and Clinical Research, Pulmonary Division, Kuopio University Hospital, Kuopio, Finland. ${ }^{2}$ School of Medicine, Faculty of Health Sciences, University of Eastern Finland, Kuopio, Finland.

Correspondence: Dr Heikki O Koskela, Unit for Medicine and Clinical Research, Pulmonary Division, Kuopio University Hospital, PL 100, 70029 KYS, Finland. E-mail: heikki.koskelaQkuh.fi

ABSTRACT Recent advances in cough research suggest a more widespread use of cough-provocation tests to demonstrate the hypersensitivity of the cough reflex arc. Cough-provocation tests with capsaicin or acidic aerosols have been used for decades in scientific studies. Several factors have hindered their use in everyday clinical work: i.e. lack of standardisation, the need for special equipment and the limited clinical importance of the response. Cough-provocation tests with hypertonic aerosols (CPTHAs) involve provocations with hypertonic saline, hypertonic histamine, mannitol and hyperpnoea. They probably act via different mechanisms than capsaicin and acidic aerosols. They are safe and well tolerated and the response is repeatable. CPTHAs can assess not only the sensitivity of the cough reflex arc but also the tendency of the airway smooth muscles to constrict (airway hyper-responsiveness). They can differentiate between subjects with asthma or chronic cough and healthy subjects. The responsiveness to CPTHAs correlates with the cough-related quality of life among asthmatic subjects. Furthermore, the responsiveness to them decreases during treatment of chronic cough. A severe response to CPTHAs may indicate poor long-term prognosis in chronic cough. The mannitol test has been stringently standardised, is easy to administer with simple equipment, and has regulatory approval for the assessment of airway hyperresponsiveness. Manual counting of coughs during a mannitol challenge would allow the measurement of the function of the cough reflex arc as a part of clinical routine.

$@$ ERSpublications

Cough-provocation tests with hypertonic aerosols offer the possibility to measure the function of the cough reflex arc even in everyday clinical work http://bit.ly/2RTOfMI

Cite this article as: Koskela HO, Nurmi HM, Purokivi MK. Cough-provocation tests with hypertonic aerosols. ERJ Open Res 2020; 6: 00338-2019 [https://doi.org/10.1183/23120541.00338-2019].

Received: 2 Dec 2019 | Accepted after revision: 23 Jan 2020

Copyright $\odot$ ERS 2020. This article is open access and distributed under the terms of the Creative Commons Attribution Non-Commercial Licence 4.0. 


\section{Introduction}

Cough-provocation tests have been used for decades in scientific investigations evaluating the sensitivity of the cough reflex arc and for assessing the antitussive effects of therapies. Several agents have been utilised, most commonly capsaicin and acidic aerosols like citric acid [1]. The cough response to these agents involve the stimulation of the transient receptor potential (TRP) vanilloid-1 (TRPV1) [2]. They are therefore labelled as TRPV1-involved cough-provocation agents in the present review although the action of acidic agents also involves other receptor types [3,4]. These tests have not become established in everyday clinical work for several reasons. There are many methods but these have not been standardised. The dilutions need to be prepared in special pharmacies and the raw materials are not universally available. In addition, a nebuliser is needed and this introduces several problems related to calibration, cleaning and maintenance of the device. The results of the tests are considered to have of limited clinical significance due to the large variation in cough reflex sensitivity in the normal population $[1,5]$.

Recent advances in cough research suggest a more widespread use of cough-provocation tests. Chronic cough is nowadays considered a manifestation of cough hypersensitivity syndrome, indicating a long-standing hypersensitivity of the cough reflex arc regardless of the background disorder [6, 7]. At the moment, this condition is defined purely on the basis of symptoms. An objective demonstration of the hypersensitivity of the cough reflex arc would help to diagnose this syndrome more precisely. Furthermore, new drugs have been developed that are capable of efficiently modulating cough hypersensitivity [8]. An objective demonstration of an abnormally functioning cough reflex arc would aid in patient selection and monitoring the treatment effect.

This review describes a new group of cough-provocation tests: CPTHAs. We will discuss the possible mechanisms behind the response and evaluate the validity of the accumulated data in investigations of patients with cough. Finally, we propose a feasible and standardised way to perform a CPTHA that makes it possible to integrate testing of the cough reflex arc function into the routine assessment of the patient with respiratory symptoms.

\section{History of CPTHAs}

The development of hypertonic airway challenges started when the mechanisms behind exercise-induced asthma were resolved 40 years ago. It was proposed that evaporative water loss due to exercise-associated hyperpnoea increases the concentration of solute particles in airway surface liquid, i.e., causes hyperosmolarity $[9,10]$. This, in turn, was thought to trigger the release of bronchoconstrictive mediators from local inflammatory cells. In airway challenges with hypertonic aerosols, the hyperosmolarity of the airway surface liquid is achieved by administering via inhalation osmotically active substances into the airways [11].

It has been known for decades that in addition of bronchoconstriction, hypertonic aerosols also can trigger cough [11]. Initially, the cough response was regarded as an unspecific side effect of hypertonic aerosols. However, in 2004 it was found that asthmatic subjects exhibit a far greater cough response to inhaled mannitol than healthy individuals. This finding suggested that the cough response to mannitol could be exploited to investigate the function of the cough reflex arc in asthma [12]. Subsequently, other patient groups have also been investigated and other hypertonic agents have been utilised. The key study by Purokivi et al. revealed that the cough response to inhaled hypertonic saline correlates well with the cough response to dry air hyperpnoea [13]. This finding suggested that the mechanisms behind the cough responses to these stimuli are the same. Therefore, cough-provocation tests with hyperpnoea are included in this review and regarded as a form of CPTHA.

\section{The possible mechanisms of hypertonic aerosol-provoked cough}

In addition to cough, hypertonic aerosols induce bronchoconstriction. Since bronchoconstriction itself can provoke cough [14-17], the investigators initially assumed that the cough response was secondary to the induced bronchoconstriction. Indeed, an early study revealed a significant association between the cough response and the bronchoconstrictive response to mannitol [12]. However, it was demonstrated that asthmatic subjects cough more than healthy subjects in response to hypertonic aerosols even in that stage of the challenge when bronchoconstriction is not evident $[12,18]$. Even those asthmatic subjects not displaying a bronchoconstrictive response to mannitol still coughed more than healthy subjects [12]. Furthermore, pre-treatment with nedocromil and salbutamol, drugs that are capable of effectively inhibiting the bronchoconstrictive response to hypertonic aerosols, did not prevent the cough response to them [19, 20]. Thus, the cough response to hypertonic aerosols cannot be attributed to the induction of bronchoconstriction. Instead, the response probably involves an excitation of airway sensory nerves by hyperosmolarity. The excitation could be either direct or indirect. The latter mechanism indicates a release of sensory nerve -stimulating agents from local cells by hyperosmolarity. It will be discussed later in this review. 
In dogs and guinea pigs, hypertonic saline stimulates airway afferent A delta and C-fibres [21, 22]. The airway afferent sensory fibres can be divided to two neurochemically and functionally distinct phenotypes according to the location of their cell bodies in either the jugular or the nodose ganglia of the vagus nerve $[4,22]$. In the airways of guinea pigs, hypertonic saline selectively stimulates those A delta and C-fibres which have their cell bodies in the jugular ganglion [22, 23]. Thus, these fibres most probably mediate the afferent stimulus of the hypertonicity-provoked cough.

The normal osmolarity of the airway surface liquid is 320-340 mOsm [24]. PEDERSEN et al. [23] investigated in vitro guinea pig tracheal and bronchial preparations. They added solutions with various $\mathrm{NaCl}$ concentrations directly over the fields of interest. The activation of jugular ganglion sensory fibres started when the concentration of saline exceeded 3\% (approximately $900 \mathrm{mosmol} \cdot \mathrm{L}^{-1}$ ) and increased with concentration [23]. However, the exact mechanism through which hypertonicity excites the jugular ganglion fibres is unknown [25]. The excitation may involve an activation of a receptor, which is capable of detecting hyperosmolarity. Among the many TRP channels, TRPV1 and TRPA1 are highly expressed by C-fibres [26].

TRPV1 has been a major focus in cough research for years. It is known to be involved in the action of the capsaicin and citric acid tests [27]. However, the cough response to hypertonic aerosols does not involve TRPV1 since capsazepine, a TRPV1 antagonist that inhibits cough induced by capsaicin and citric acid, does not inhibit cough provoked by hypertonic saline [2].

TRPA1 can be activated by many environmental irritants [28]. There are some animal studies suggesting that TRPA1 might also be involved in the sensing of osmolarity $[29,30]$. The cough sensitivity to allyl isothiocyanate, a selective TRPA1 agonist, is significantly higher in patients with chronic cough than in healthy subjects [28]. The role of TRPA1 in mediating the effects of airway oxidative stress will be discussed later.

TRPV4 is expressed in airway epithelium, macrophages, smooth muscle and airway A delta sensory fibres, but not in C-fibres. TRPV4 is thought to act as a sensor of osmotic homeostasis [31, 32]. However, administration of the TRPV4 antagonist GSK2193874 did not inhibit the cough response to hypertonic saline in guinea pigs suggesting that this receptor is not involved in hypertonicity-induced cough [25].

Airway $\mathrm{C}$ fibres also express $\mathrm{P} 2 \mathrm{X} 3$ receptors, which are activated by adenosine triphosphate (ATP). Recent studies have revealed that P2X3 is very probably involved in chronic cough [8]. ATP is a molecule with several potential functions, such as an energy source, a transmitter, a paracrine signalling molecule and an extracellular reporter of ischaemia, damage and inflammation [33]. It has been shown that human lens, retinal, corneal and conjunctival epithelial cells release ATP in response to hypertonicity [34, 35]. Thus, it is possible that hypertonicity could activate airway C-fibre P2X3 receptors by stimulating ATP release from airway epithelial cells.

Ambient hypertonicity causes shrinkage of cells. It is noteworthy that the sensory fibres with their cell body in the jugular ganglion reach up to the superficial layers of the epithelium, where the osmotic stress caused by inhaled hypertonic aerosols is most severe [36]. Shrinkage of cells induces a series of regulatory responses but these are beyond the scope of this review [37]. However, it is possible that one way through which hypertonicity could activate cough-involved sensory fibres may involve the shrinkage of these fibres.

\section{Short descriptions of the main methods to perform CPTHAs}

As with all CPTHAs, hypertonic saline challenge was initially developed to measure the tendency of airway smooth muscle to constrict in response to external stimuli, i.e. the airway hyperresponsiveness. A method involving a pre-treatment with inhaled salbutamol has been developed for investigating the cough response to hypertonic saline [20]. Salbutamol can efficiently prevent the hypertonic saline-induced bronchoconstriction but does not affect the cough reflex sensitivity in conventional doses [38-43]. Thus, the bronchoconstriction-provoked cough is eliminated, and the resulting cough is probably provoked exclusively by hypertonicity. In airway challenges with hypertonic saline, one needs to use high-output ultrasonic nebulisers that generate aerosols of high density [20,44, 45]. Prior to the test, spirometry is performed before and after administration of $0.4 \mathrm{mg}$ of inhaled salbutamol. Subsequently, the subject inhales isotonic phosphate-buffered saline (osmolality $300 \mathrm{mOsm} \cdot \mathrm{kg}^{-1}$ ) for $2 \mathrm{~min}$ using tidal breathing. The coughs occurring during and in the $2 \mathrm{~min}$ after the inhalation are counted. This number is subtracted from the coughs provoked by each hypertonic solution. Subsequently, the subjects similarly inhale phosphate-buffered saline solutions with osmolalities of $600,900,1200,1500,1800$ and $2100 \mathrm{mOsm} \cdot \mathrm{kg}^{-1}$. The spirometry is repeated at the end of the test. The cough response is expressed as the osmolality needed to provoke 15 cumulative coughs [20] or as the cumulative number of coughs divided by the final osmolality administered [13]. Hypertonic saline has also been administered without any pre-medication, using a constant saline concentration but in a stepwise manner with increasing durations. The response has been expressed as the total number of coughs provoked during the inhalations and 10 min afterwards [45]. 
In the hypertonic histamine challenge, a hand-held ultrasonic nebuliser is used [18, 46]. Histamine diphosphate is dissolved in hypertonic phosphate-buffered saline to achieve solutions containing 0.0075 , $0.015, \quad 0.03,0.06,0.125,0.25, \quad 0.5, \quad 1.0, \quad 2.0, \quad 4.0$ and $8.0 \mathrm{mg}$ of histamine. $\mathrm{mL}^{-1}$. Hypertonic phosphate-buffered saline is prepared by using larger concentrations of $\mathrm{NaCl}$ than in standard phosphate-buffered saline, leading to the solutions having osmolality values of $1522-1577 \mathrm{mOsm} \cdot \mathrm{kg}^{-1}$. Each solution is inhaled for $2 \mathrm{~min}$ with tidal breathing. Spirometry is performed twice at $90 \mathrm{~s}$ from the end of each inhalation. The coughs are counted during the $90 \mathrm{~s}$ observation period after the inhalation. The cough response is expressed as the cumulative number of coughs divided by the final histamine concentration utilised. The bronchoconstrictive response is also reported.

The mannitol test is performed with capsules containing mannitol powder and a disposable inhaler [47]. The challenge kit is commercially available. Following baseline spirometry, an empty capsule is administered with an inhalation to total lung capacity. Deep inspiration can provoke cough in the most sensitive individuals [48]. The test continues with increasing doses $(5,10,20,40,2 \times 40,4 \times 40,4 \times 40$ and $4 \times 40 \mathrm{mg}$ ) of mannitol. After the empty capsule, as well as after every dose, all coughs occurring during the inhalation and during the $60 \mathrm{~s}$ period following the inhalation are recorded. In cases when more than one capsule is utilised, the coughs occurring between capsules are recorded as well and the $60 \mathrm{~s}$ time period starts after the inhalation of the last capsule. The spirometry is performed twice when the $60 \mathrm{~s}$ observation period has passed. The cough response is expressed as the first non-cumulative dose of mannitol that provokes five coughs (C5) or as the cumulative number of coughs divided by the cumulative dose of mannitol administered [12, 48, 49]. The bronchoconstrictive response is also reported.

Several methods have been utilised to investigate the cough responsiveness to hyperpnoea. Dry air at subfreezing $[50,51]$ and at room temperature $[13,45]$ have been used. In some studies, a single challenge at a high ventilation level was exploited $[45,50,51]$, in another publication, stepwise increasing ventilation levels were utilised [13]. Some investigators have utilised salbutamol pre-treatment before hyperpnoea [13], but others have not adopted this approach $[45,50,51]$. The cough response has been expressed either as the absolute number of coughs induced by the challenge $[45,50,51]$ or by the number of cumulative coughs divided by the level of ventilation achieved [13]. The bronchoconstrictive response is also reported.

\section{Description of the cough response to CPTHAs}

The speed of the cough response may differ between CPTHAs and TRPV1-involved challenges. In guinea pigs exposed to 10-min inhalations of various cough provoking agents, the coughing started on average $53 \mathrm{~s}$ after the start of citric acid inhalation, whereas the coughing in response to hypertonic saline appeared not until $100 \mathrm{~s}$ from the start of inhalation [25]. This difference in the speed of the responses can also be detected in humans. The cough response to TRPV1-involved cough provocation agents is usually immediate and transient $[1,48]$. On the contrary, when utilising a 2-min tidal breathing technique for the cough provocation with hypertonic saline, subjects usually can refrain from coughing during the inhalation and cough most frequently during the first minute after nebulisation [20]. Similarly, subjects can usually refrain from coughing during a three-minute hyperpnoea of dry air and cough most frequently during the first minute after the challenge [13]. Coughing can continue for several minutes after these challenges. However, the cough response to mannitol is usually rapid. Compared with other CPTHAs, the rise in the osmolarity of the airway lining fluid is probably much faster in the mannitol challenge, which probably explains the differences in the time courses of the responses.

In some subjects, the cough response to CPTHAs can be severe. At high coughing frequencies, it is more reliable to count the coughs from a video recording than attempting to measure them during the test. However, the agreement between simultaneous and video counting of coughs is rather good in CPTHAs [52].

\section{The association of the response to CPTHAs with sex and age}

Females are more sensitive than males to the cough-provoking effect of hypertonic saline [20] and mannitol $[48,49]$. A similar sex difference has been reported also in the sensitivity to the TRPV1-involved cough provoking agents [53-58]. A large study involving 600 subjects has demonstrated that the cough sensitivity to capsaicin is weakly associated with advanced age [57]. Such an association has not been documented in CPTHAs but the populations may have been too small to reveal such a weak association.

\section{The repeatability of the cough response to CPTHAs}

Most investigators have reported the repeatability of the cough response to CPTHAs to be good. In one study, an airway challenge with hypertonic histamine was carried out twice in 32 asthmatic subjects, a median 3 days apart. The intra-class correlation coefficient (ICC) of the coughs-to-concentration ratio was 0.97 [18]. In 18 subjects with chronic cough, the hypertonic saline cough provocation test with salbutamol pre-treatment was performed twice 2-14 days apart. The ICC of the osmolality to provoke 15 coughs was 
0.90 [20]. In 24 subjects with asthma, the mannitol challenge was performed first without pre-treatment and then with placebo pre-treatment 5-21 days apart. The ICC of the coughs-to-dose ratio was 0.91 [19]. There is one study that observed only moderate repeatability. It included just 13 subjects with chronic, very mild cough and six healthy subjects. The mannitol challenge was performed twice, separated by 1 week. The ICC of the mannitol C5 was a mere 0.59 [59]. It is possible that the repeatability of the coughs-to-dose ratio is better than that of the cough threshold values like C5 in the mannitol challenge.

\section{Safety and tolerability of CPTHAs}

Airway challenges with hypertonic aerosols have been conducted for decades to investigate airway hyperresponsiveness in everyday clinical work among thousands of subjects and there are no reports of serious side effects $[60,61]$. In particular, the mannitol challenge has undergone extensive evaluation and has received regulatory approval in the USA, Europe, Australia and South Korea [47]. Airway challenges with hypertonic saline and mannitol do not cause significant blood oxygen desaturation [13, 61], nor does hyperpnoea when performed after salbutamol pre-treatment [13]. The tolerability of the mannitol challenge, as measured on a visual analogue scale, has been found to be similar to that of the citric acid test [48]. Hypertonic aerosols can provoke a severe cough response and the tolerability is correlated with the number of provoked coughs. Some subjects discontinue the tests due to excessive coughing [48]. Some subjects may also experience exhaustion due to cough, nausea, headache and pharyngolaryngeal pain $[48,61]$. The tolerability of CPTHAs might be improved by terminating the test immediately when a pre-determined cough threshold value has been achieved. However, such a practice would preclude the use of CPTHA to investigate airway hyperresponsiveness during the same session. As CPTHAs can induce bronchoconstriction, they should preferably be administered either in a stepwise manner with spirometry at each step, or after salbutamol pre-treatment $[13,20]$.

\section{The ability of CPTHAs to differentiate subjects with asthma from healthy subjects}

Because airway challenges with hypertonic aerosols were originally developed to investigate airway hyperresponsiveness, many early CPTHA studies focused on asthmatic subjects. In all studies including asthmatic and healthy subjects, the cough response to CPTHAs has been shown to be much more severe in asthmatic subjects (fig. 1). Table 1 shows the studies, which either report the sensitivity and the specificity values or provide an access to original data to allow their calculation $[12,13,18,20,45,48,62]$. In these studies, the asthmatic subjects have represented classic asthma with objectively documented variable airway obstruction but in most of them, the inclusion criteria have included cough as one of the symptoms.

Cough patients with asthma are usually more sensitive to CPTHAs than cough patients without this disorder (fig. 2) [20, 48, 62, 63]. However, one study did not corroborate this. In that study, subjects with chronic idiopathic cough coughed more than asthmatic subjects in response to various CPTHAs [45]. This discordant result may be explained by the selection of the participants. The inclusion criteria for the subjects with idiopathic cough included symptomatic cough lasting for at least 2 months and a positive response to a preceding capsaicin cough provocation test. On the contrary, the asthmatic patients suffered
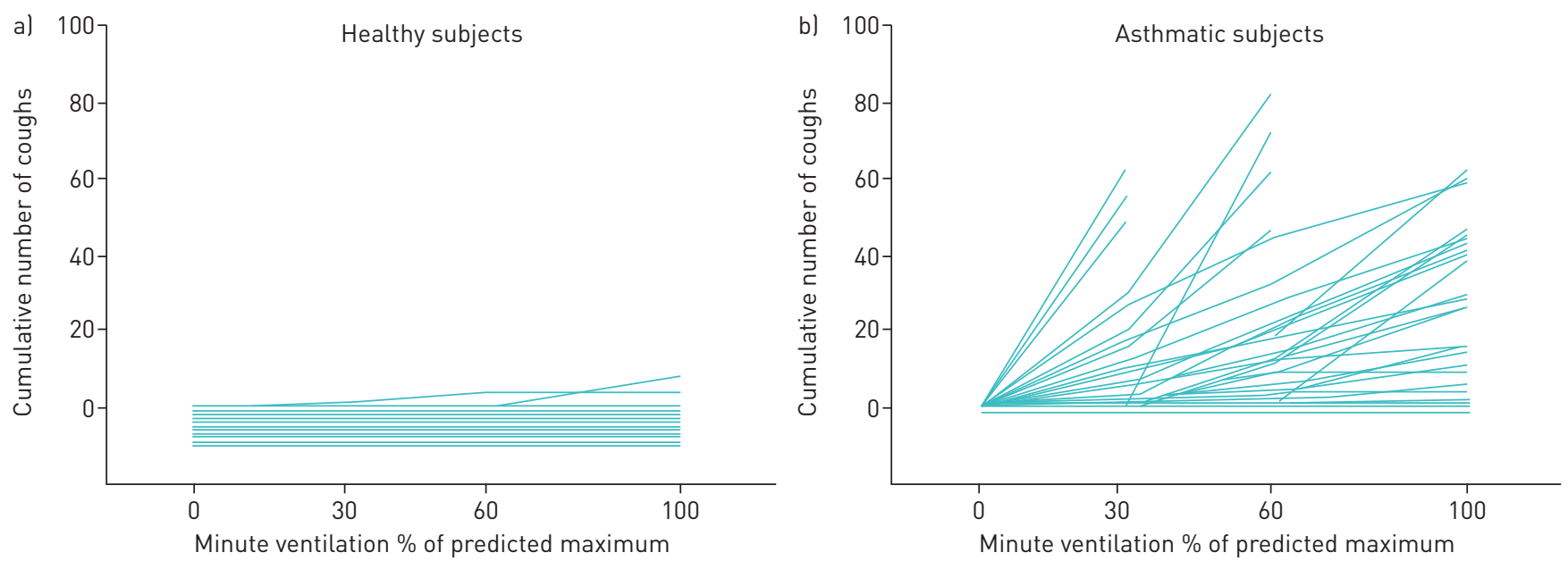

FIGURE 1 The cumulative number of coughs in relation to minute ventilation evoked by isocapnic hyperpnoea of dry air challenge in 10 healthy (a) and 30 asthmatic (b) subjects. The horizontal lines at or below zero indicate subjects who did not cough at all. Reproduced from [13] with permission. 


\section{TABLE 1 The ability of cough provocation tests with hypertonic aerosols to differentiate subjects with asthma from healthy} subjects

\section{First author [Ref.] Agent}

\section{Cut-off value}

$\geqslant 0.8$ coughs $/ 100 \mathrm{mg}$

$\geqslant 17.2$ coughs $/ 100 \mathrm{mg}$

$\geqslant 48$ coughs during the whole test

$\leqslant 1428 \mathrm{mOsm} \cdot \mathrm{kg}^{-1}$ to provoke 15 coughs

$\geqslant 0.0005$ coughs $\cdot \mathrm{mOsm}^{-1} \cdot \mathrm{kg}^{-1}$

$\geqslant 5$ coughs during the whole test

$\geqslant 12.2$ coughs $\cdot \mathrm{mg}^{-1} \cdot \mathrm{mL}^{-1}$

$\geqslant 69.2$ coughs $\cdot \mathrm{mg}^{-1} \cdot \mathrm{mL}^{-1}$

$\geqslant 0.085$ coughs/MVV\%

$\geqslant 11$ coughs during the whole test
Subjects with Sensitivity asthma $n$
Healthy subjects $\mathbf{n}$

Specificity

$\begin{array}{lccc}37 & 78 \%^{\#} & 10 & 100 \%^{\#} \\ 11 & 91 \%^{\#} & 25 & 92 \%^{\#} \\ 16 & 80 \%{ }^{\#} & 21 & 76 \%^{\#} \\ 26 & 62 \%^{\#} & 19 & 100 \%^{\#} \\ 36 & 89 \%^{\#} & 14 & 93 \%^{\#} \\ 16 & 100 \%{ }^{\#} & 21 & 81 \%^{\#} \\ 32 & 62 \%{ }^{\#} & 15 & 93 \%^{\#} \\ 30 & 80 \% & 25 & 96 \% \\ 36 & 75 \%{ }^{\#} & 14 & 100 \%^{\#} \\ 15 & 60 \%{ }^{\#} & 21 & 81 \%^{\#}\end{array}$

\#: Calculated from the original data, based on the largest obtainable Youden index. MVV\%: minute ventilation level expressed as percentage of the predicted maximal voluntary ventilation.
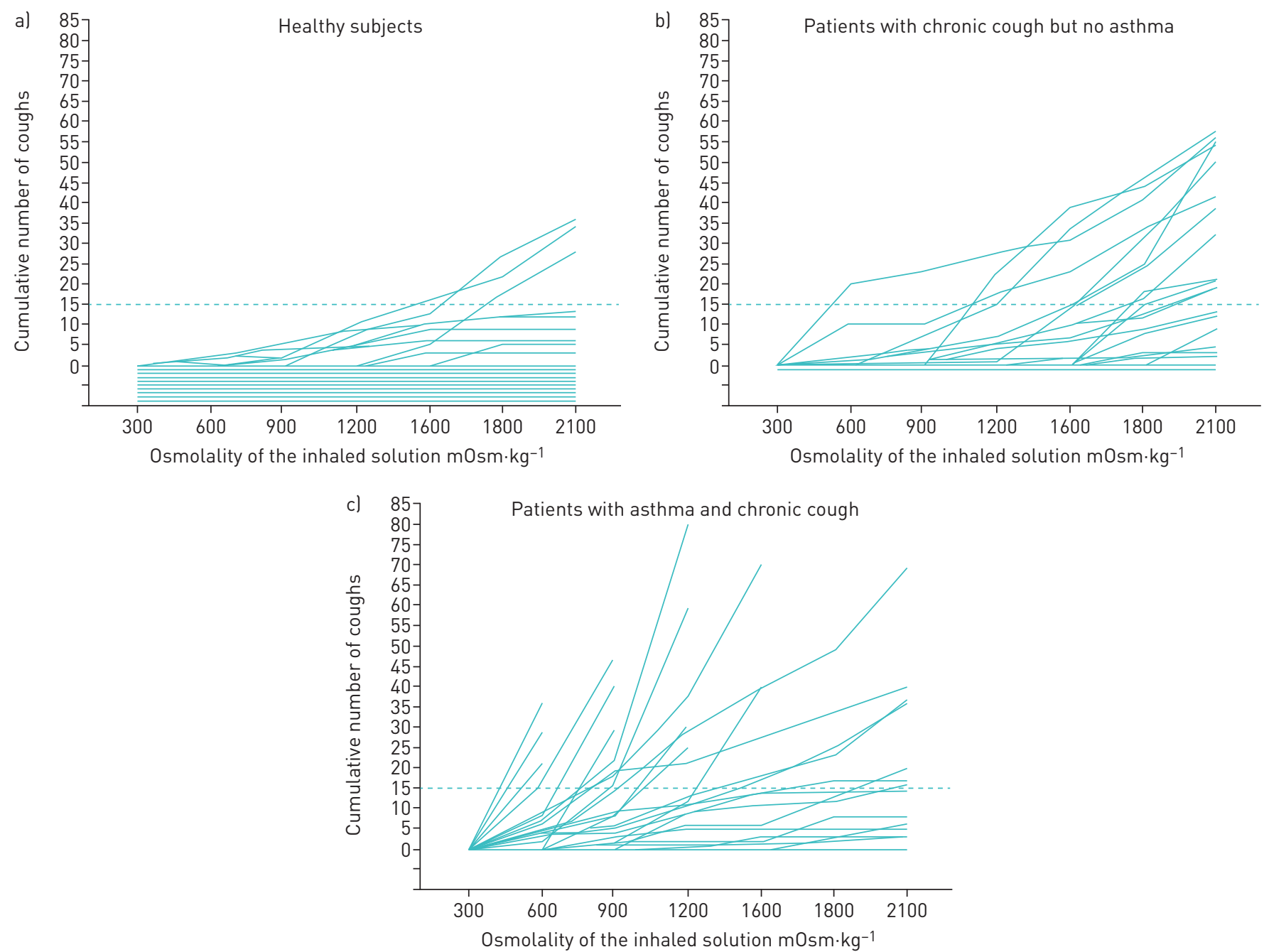

FIGURE 2 The cumulative number of coughs evoked by hypertonic saline challenge in 19 healthy subjects (a), 21 patients with chronic cough but without asthma (b), and 26 asthmatic patients with chronic cough (c). The dashed line indicates 15 cumulative coughs. The horizontal lines at or below zero indicate subjects who did not cough at all. Reproduced from [20] with permission. 
from mild asthma and the inclusion criteria included neither symptomatic cough nor capsaicin sensitivity. Furthermore, the investigators did not relate the number of coughs to the amount of the bronchoconstrictive agent administered. However, importantly, that study revealed that the cough response to hyperpnoea, hypertonic saline and mannitol could differentiate the asthmatic subjects from healthy subjects more clearly than the bronchoconstrictive response to these stimuli [45]. This observation strongly supports the rationale of measuring the cough response, in addition to the bronchoconstrictive response, during hypertonic airway challenges in the diagnostic evaluation of asthma.

TRPV1-involved cough provocation tests often fail to differentiate patients with classic asthma from healthy subjects, especially when utilising the traditional threshold values like C5 to express the cough sensitivity [4, 45, 58, 64-76]. Therefore, the ability of CPTHAs to clearly differentiate asthmatic and healthy subjects is a special feature among cough-provocation tests. The asthmatic airway inflammation involves eosinophils, mast cells and lymphocytes [77]. It is possible that some of these cells might be able to sense hyperosmolarity and to secrete substances that activate jugular ganglion sensory fibres. Mediator secretion from mast cells is triggered by the increase in ambient osmolarity $[78,79]$. Mast cells secrete, among other substances, prostaglandin D2 [80]. The prostaglandin D receptor (PTGDR) is expressed in jugular ganglion sensory neurons [81] and prostaglandin D2 evokes coughing in guinea pigs [82]. However, nedocromil and salbutamol, which are capable of inhibiting mast cell mediator release [80, 83], were unable to inhibit the cough response to CPTHAs $[13,19,20,51]$. These findings speak against the role of mast cell-derived mediators in the hyperosmolarity-induced cough.

It is also possible that the products of the inflammatory cells could sensitise airway sensory fibres. In mice, cough responses to inhaled irritants are enhanced by eosinophil major basic protein [84]. However, the cough sensitivity to CPTHAs neither correlates with the exhaled air nitric oxide concentration, a measure of eosinophilic airway inflammation [20,63], nor with airway hyperresponsiveness to histamine [12, 20, 63]. Furthermore, baseline cough responsiveness to CPTHAs could not predict the clinical outcomes either when initiating or terminating therapy with inhaled corticosteroids among subjects with chronic cough and/or asthma $[63,85]$. Therefore, it seems that the mechanism behind the special sensitivity to CPTHAs in asthma is not directly related to the corticosteroid-sensitive, eosinophilic airway inflammation.

Inflammation increases the production of reactive oxygen (ROS) and nitrogen (RNS) species, leading to imbalance of oxidants and antioxidants, termed as oxidative stress [77]. Phospholipids, proteins and nucleic acids are oxidised by ROS causing major cellular dysfunction [86]. Oxidative stress and associated compounds stimulate afferent C-fibres, most probably by activating TRPA1, but TRPV1 and P2X3 may also contribute [87]. Exhaled breath condensate (EBC) concentration of 8-isoprostane reflects airway oxidative stress. It is higher in patients with chronic cough than in healthy subjects and, among the cough patients, correlates with the impairment in the cough-related quality of life [88]. In asthma, high concentration of 8-isoprostane in EBC is associated with poor cough-related quality of life and with the degree of cough responsiveness to dry air hyperpnoea. Among non-smoking asthmatic subjects, the concentration of 8-isoprostane also correlates with the cough responsiveness to hypertonic saline [89]. Thus, rather than inflammation per se, it may be its consequence, the oxidative stress, that explains the special cough responsiveness to CPTHAs in asthma.

\section{The ability of CPTHAs to differentiate subjects with non-specific chronic cough from healthy subjects}

Several studies have shown that the cough response to CPTHAs can differentiate subjects with chronic cough due to various reasons from their non-coughing counterparts. Table 2 presents the studies which either report the sensitivity and specificity values or provide an access to original data to permit their calculation [20,45, 48, 49, 59]. It is noteworthy that the cough sensitivity to mannitol not only differentiates patients with chronic cough from healthy subjects but also from those with other airway symptoms [49]. The report of Singapuri et al. differs from the other studies, which are presented in table 2, by including patients with very mild cough. Their mean Leicester Cough Questionnaire (LCQ) total score was as high as 17.3 [59]. This may explain the only modest sensitivity of the mannitol test in their hands. In addition to the studies listed in table 2, one study has reported that patients with chronic cough are more likely than healthy controls to cough in response to cold air hyperpnoea but the sensitivity and specificity values were not presented [50].

\section{The correlation between the cough sensitivity to CPTHAs and the subjectively experienced severity of cough}

There seems to be an association between the cough sensitivity to CPTHAs and the subjectively experienced severity of cough among asthmatic subjects but not among those with non-specific chronic cough. In 36 subjects with asthma, the cough responses to hypertonic saline and isocapnic hyperpnoea of 
TABLE 2 The ability of cough provocation tests with hypertonic aerosols to differentiate subjects with chronic cough from healthy subjects

\begin{tabular}{|c|c|c|c|c|c|c|}
\hline $\begin{array}{l}\text { First author } \\
\text { [Ref.] }\end{array}$ & Agent & Cut-off value & $\begin{array}{l}\text { Subjects with } \\
\text { chronic cough } n\end{array}$ & Sensitivity & $\begin{array}{l}\text { Healthy } \\
\text { subjects } \mathrm{n}\end{array}$ & Specificity \\
\hline SINGAPURI [59] & Mannitol & $\begin{array}{l}\text { Dose of mannitol } \leqslant 550 \mathrm{mg} \text { to cause } \\
5 \text { coughs }\end{array}$ & 13 & $62 \%$ & 16 & $81 \%$ \\
\hline KoSKELA [49] & Mannitol & $\geqslant 12.0$ coughs $\cdot 100 \mathrm{mg}^{-1}$ & 17 & $82 \%{ }^{\#}$ & 15 & $100 \%{ }^{\#}$ \\
\hline JoHANSSON [45] & Mannitol & $\geqslant 69$ coughs during the whole test & 22 & $95 \%{ }^{\#}$ & 21 & $90 \%{ }^{\#}$ \\
\hline NuRmi [48] & Mannitol & $\geqslant 5.4$ coughs $\cdot 100 \mathrm{mg}^{-1}$ & 36 & $92 \%{ }^{\#}$ & 25 & $64 \%{ }^{\#}$ \\
\hline JoHANSSON [45] & Hypertonic saline & $\geqslant 11$ coughs during the whole test & 21 & $95 \%{ }^{\#}$ & 21 & $95 \%{ }^{\#}$ \\
\hline JOHANSSON [45] & Dry air hyperpnoea & $\geqslant 14$ coughs during the whole test & 23 & $95 \%{ }^{\#}$ & 21 & $86 \%{ }^{\#}$ \\
\hline
\end{tabular}

dry air were significantly greater among subjects with insufficient asthma control than among subjects with good asthma control [90]. Furthermore, the LCQ total score correlated significantly with the hypertonic saline coughs-to-dose ratio $(\mathrm{R}=-0.66 ; \mathrm{p}<0.001)$ and the hyperpnoea coughs-to-ventilation ratio $(\mathrm{R}=-0.49 ; \mathrm{p}=0.002)$ [90]. Importantly, asthma control and cough-related quality of life were more closely associated with cough responsiveness to these CPTHAs than with traditional asthma severity indices, such as exhaled nitric oxide concentration, spirometric indices, bronchodilator response and ambulatory peak flow variation. On the contrary, in a study examining 43 subjects with non-specific chronic cough, hypertonic saline coughs-to-osmolality value did not correlate statistically significantly with LCQ total score [63]. Furthermore, a recent study failed to find a statistically significant association between the cough response to mannitol and the LCQ total score in 36 subjects with chronic cough due to various reasons [48].

\section{The ability of the CPTHAs to monitor the resolution of cough}

There are three prospective, follow-up trials in which CPTHAs have been performed repeatedly during the treatment of patients exhibiting respiratory symptoms. In a study involving asthmatic subjects, the change in the severity of the cough response to mannitol correlated well with changes in the symptom sum and subjective cough severity after the commencement of treatment with inhaled budesonide [12]. In another study, 16 steroid-naïve asthmatics and 10 non-asthmatic, symptomatic patients received inhaled beclomethasone for 8 weeks. In the asthmatic patients, both the subjective cough severity and the cough response to hypertonic histamine decreased statistically significantly whereas neither value changed statistically significantly in the non-asthmatic, symptomatic patients [91]. In another study, 43 subjects with chronic cough received inhaled budesonide for 12 weeks. During the treatment, the cough sensitivity to hypertonic saline decreased only among those individuals exhibiting a clinically important improvement in the cough-related quality of life [63]. Thus, the responsiveness to CPTHAs declines during successive treatment of chronic cough and these tests can be used in clinical trials to objectively document the resolution of cough.

\section{The ability of CPTHAs to predict the long-term prognosis of chronic cough}

Only one study has investigated this issue; it examined 89 subjects with chronic cough, both asthmatic and non-asthmatic. In a multivariate analysis, regular cough at 5 years after the initial evaluation was associated with either chronic rhinitis or oesophageal reflux disease, baseline mild airway responsiveness to histamine and baseline strong cough responsiveness to hypertonic saline [92]. This study suggested that a high sensitivity to CPTHAs may predict a long-term dysfunction of the cough reflex arc.

\section{The ability of the CPTHAs to predict the outcome of the commencement or discontinuation of inhaled corticosteroids}

The bronchoconstrictive response to hypertonic aerosols has been shown to predict the symptomatic response to inhaled corticosteroids [93, 94] and to predict the outcome after their discontinuation [95]. Therefore, it was considered important to investigate whether the cough response to them could also be predictive in these settings. However, these studies have been negative. In one study, the cough sensitivity to hypertonic saline was determined in 43 subjects with chronic cough for various reasons. A treatment with inhaled budesonide was initiated and continued for 3 months. The symptomatic response, in terms of 
LCQ total score change, could not be predicted by the baseline cough sensitivity to hypertonic saline [63]. Another study examined 55 well-controlled asthmatic subjects with combination asthma therapy. A stepwise reduction of medication was started with the goal of terminating all inhaled therapies. A cough provocation test with hypertonic saline was performed before each step. The cough response to it could not predict the outcome (exacerbation or not) of the medication reductions [85]. These findings suggest that the cough response to CPTHAs cannot be used to predict the role of corticosteroids in the management of a patient's respiratory symptoms.

\section{Comparisons between CPTHAs and TRPV1-involved cough provocation tests}

There are very few human studies in which the same subjects have been challenged with both a CPTHA and TRPV1-involved tests. CHO et al. investigated 49 patients with chronic cough and 15 healthy controls, challenging them with cold air hyperpnoea and capsaicin [50]. Those with an increased cough sensitivity to capsaicin also exhibited the largest cough responses to cold air hyperpnoea and there was a statistically significant correlation between the responses [50]. In the study by JoHANsson et al. [45], subjects with idiopathic chronic cough were much more sensitive to capsaicin than subjects with mild asthma and furthermore, the former group also showed more severe cough responses to mannitol, dry air hyperpnoea and hypertonic saline. Finally, Nurmi et al. [48] challenged 36 subjects with chronic cough and 25 healthy subjects with mannitol and citric acid. In the subjects with chronic cough, the responsiveness to mannitol correlated well with that to citric acid $(\mathrm{r}=0.65, \mathrm{p}<0.001$; fig. 3$)$ [48]. These findings show that the responses to CPTHAs and TRPV1-mediated cough provocation tests correlate rather well in spite of the differences in the mechanisms of action. These findings suggest that the hypersensitivity of the cough reflex arc in chronic cough may not be linked to a specific receptor in the airway sensory nerve cell. However, this view has also been challenged [28].

\section{Conclusions}

A strong body of evidence shows that CPTHAs can effectively differentiate both asthmatic subjects and subjects with chronic cough from their healthy counterparts. CPTHAs are safe and well tolerated and the response is repeatable. There is preliminary evidence that they may be able to predict the prognosis of chronic cough and that in clinical trials, they can mirror the resolution of cough. When performed without pre-medication, these tests can assess both the tendency of the airway muscles to constrict and the sensitivity of the cough reflex arc. These two response types are independent. Therefore, recording of both would provide comprehensive information about a patient complaining of various long-term respiratory symptoms.

There are several different ways to perform CPTHAs. If performed after salbutamol pre-treatment, the hypertonic saline and the dry air hyperpnoea tests allow an investigation of the cough reflex without the confusing effects of induced bronchoconstriction [20]. Special equipment is needed to perform them and therefore, these tests are most suitable for research purposes aiming to explore the mechanisms of hypertonicity-provoked cough. The mannitol test may be more suitable for clinical studies in large populations. In addition, it could also be used in everyday clinical work. It has been stringently standardised, it is easy to administer with simple equipment and has regulatory approval for assessment of

FIGURE 3 The correlation between the coughs-to-dose ratios (CDR) of mannitol and citric acid among 36 subjects with chronic cough. $r=0.65$, $\mathrm{p}<0.001$. Reproduced from [48] with permission.

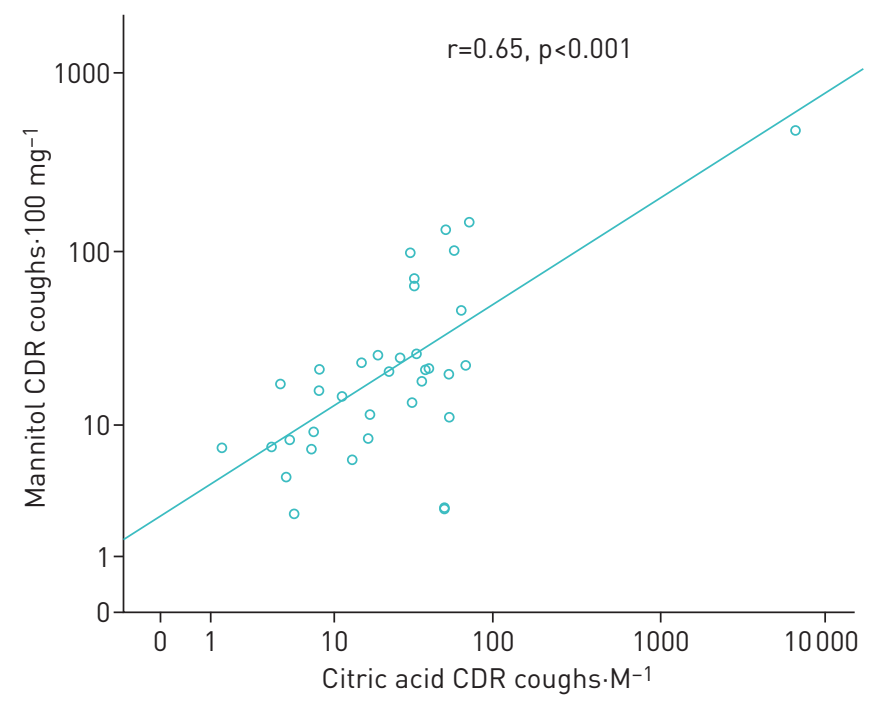


airway hyperresponsiveness [48]. For these reasons it is already widely used around the world. We recommend manual counting of the coughs during the mannitol test, in addition to the standard assessment of the bronchoconstrictive response. Video recordings and cough counting after the test are not mandatory [52]. We suggest a cut-off value of 5 coughs per $100 \mathrm{mg}$ in order to gain high sensitivity to demonstrate an abnormally functioning cough reflex arc by mannitol test [48] and 12 coughs per $100 \mathrm{mg}$ in order to gain high specificity [49]. By these means, the measurement of the function of the cough reflex arc can now be transferred from research laboratories to the routine assessment of patients with respiratory symptoms in the clinic.

Acknowledgements: We thank Ewen MacDonald (University of Eastern Finland, Kuopio, Finland) for the language check.

Conflict of interest: H.O. Koskela reports grants from Kuopion Seudun Hengityssäätiö Foundation and Hengityssairauksien Tutkimussäätiö during the current work; personal fees from Mundipharma Ltd, Orion Pharma Ltd, Oy, Eli Lilly Finland Ltd, Boehringer Ingelheim Finland Ltd and MSD Finland Ltd, as payments for giving scientific lectures in gatherings organised by medical companies; personal fees from Takeda Leiras Ltd, Boehringer Ingelheim Ltd, Mundipharma Ltd and AstraZeneca Ltd, to visit international scientific meetings; and owning shares of Orion Pharma Ltd. H.M. Nurmi reports personal fees from Boehringer-Ingelheim Finland Ltd and Roche Ltd, as lecturer fees/ consulting fees in gatherings organised by medical companies; personal fees from Boehringer-Ingelheim Finland Ltd, Roche Ltd and Sanofi Genzyme Ltd as congress travel grants to visit international scientific meetings; and grants from the Kuopio region Respiratory Foundation and the North Savo Regional Fund of the Finnish Cultural Foundation for previous studies, outside the submitted work. M.K. Purokivi reports personal fees from Boehringer-Ingelheim Finland Ltd for lecturing and work preparing educational material for healthcare professionals, and travel and accommodation costs to attend the ERS International Congress (via employer, Kuopio University Hospital) from Roche, all outside the submitted work.

\section{References}

1 Morice AH, Fontana GA, Belvisi MG, et al. ERS guidelines on the assessment of cough. Eur Respir J 2007; 29: $1256-1276$.

2 Lalloo UG, Fox AJ, Belvisi MG, et al. Capsazepine inhibits cough induced by capsaicin and citric acid but not by hypertonic saline in guinea pigs. J Appl Physiol 1995; 79: 1082-1087.

3 Rai ZL, Fowles HE, Wright $\mathrm{C}$, et al. The effect of $\mathrm{pH}$ on citric acid cough challenge: A randomised control trial in chronic cough and healthy volunteers. Respir Physiol Neurobiol 2018; 257: 51-54.

4 Belvisi MG, Birrell MA, Khalid S, et al. Neurophenotypes in airway diseases. Insights from translational cough studies. Am J Respir Crit Care Med 2016; 193: 1364-1372.

5 Wallace E, Guiu Hernandez E, Ang A, et al. A systematic review of methods of citric acid cough reflex testing. Pulm Pharmacol Ther 2019; 58: 101827.

6 Chung KF. Chronic 'cough hypersensitivity syndrome': a more precise label for chronic cough. Pulm Pharmacol Ther 2011; 24: 267-271.

7 Morice AH, Faruqi S, Wright CE, et al. Cough hypersensitivity syndrome: a distinct clinical entity. Lung 2011; 189: 73-79.

8 Abdulqawi R, Dockry R, Holt K, et al. P2X3 receptor antagonist (AF-219) in refractory chronic cough: a randomised, double-blind, placebo-controlled phase 2 study. Lancet 2015; 385: 1198-1205.

9 Strauss RH, McFadden ER, Ingram RH, et al. Influence of heat and humidity on the airway obstruction induced by exercise in asthma. J Clin Invest 1978; 61: 433-440.

10 Anderson SD, Schoeffel RE, Follet R, et al. Sensitivity to heat and water loss at rest and during exercise in asthmatic patients. Eur J Respir Dis 1982; 63: 459-471.

11 Schoeffel RE, Anderson SD, Altounyan RE. Bronchial hyperreactivity in response to inhalation of ultrasonically nebulised solutions of distilled water and saline. Br Med J (Clin Res Ed) 1981; 283: 1285-1287.

12 Koskela HO, Hyvarinen L, Brannan JD, et al. Coughing during mannitol challenge is associated with asthma. Chest 2004; 125: 1985-1992.

13 Purokivi M, Koskela H, Brannan JD, et al. Cough response to isocapnic hyperpnoea of dry air and hypertonic saline are interrelated. Cough 2011; 7: 8-8.

14 Chausow AM, Banner AS. Comparison of the tussive effects of histamine and methacholine in humans. J Appl Physiol Respir Environ Exerc Physiol 1983; 55: 541-546.

15 Ohkura N, Fujimura M, Nakade Y, et al. Heightened cough response to bronchoconstriction in cough variant asthma. Respirology 2012; 17: 964-968.

16 Hara J, Fujimura M, Ohkura N, et al. The measurement of cough response to bronchoconstriction induced by methacholine inhalation in healthy subjects: An examination using the Astograph method. Exp Lung Res 2017; 43: 240-248.

17 Satia I, Badri H, Woodhead M, et al. The interaction between bronchoconstriction and cough in asthma. Thorax 2017; 72: 1144-1146.

18 Koskela HO, Kontra KM, Purokivi MK, et al. Interpretation of cough provoked by airway challenges. Chest 2005 128: 3329-3335.

19 Koskela HO, Martens R, Brannan JD, et al. Dissociation in the effect of nedocromil on mannitol-induced cough or bronchoconstriction in asthmatic subjects. Respirology 2005; 10: 442-448.

20 Koskela HO, Purokivi MK, Kontra KM, et al. Hypertonic saline cough provocation test with salbutamol pre-treatment: evidence for sensorineural dysfunction in asthma. Clin Exp Allergy 2008; 38: 1100-1107.

21 Pisarri TE, Jonzon A, Coleridge HM, et al. Vagal afferent and reflex responses to changes in surface osmolarity in lower airways of dogs. J Appl Physiol 1992; 73: 2305-2313.

22 Ricco MM, Kummer W, Biglari B, et al. Interganglionic segregation of distinct vagal afferent fibre phenotypes in guinea-pig airways. J Physiol (Lond) 1996; 496: 521-530. 
23 Pedersen KE, Meeker SN, Riccio MM, et al. Selective stimulation of jugular ganglion afferent neurons in guinea pig airways by hypertonic saline. J Appl Physiol 1998; 84: 499-506.

24 Kotaru C, Hejal RB, Finigan JH, et al. Desiccation and hypertonicity of the airway surface fluid and thermally induced asthma. J Appl Physiol 2003; 94: 227-233.

25 Buday T, Kovacikova L, Ruzinak R, et al. TRPV4 antagonist GSK2193874 does not modulate cough response to osmotic stimuli. Respir Physiol Neurobiol 2017; 236: 1-4.

26 Patil MJ, Sun H, Ru F, et al. Targeting C-fibers for peripheral acting anti-tussive drugs. Pulm Pharmacol Ther 2019; 56: 15-19.

27 Lee L, Ni D, Hayes D, et al. TRPV1 as a cough sensor and its temperature-sensitive properties. Pulm Pharmacol Ther 2011; 24: 280-285.

28 Long L, Yao H, Tian J, et al. Heterogeneity of cough hypersensitivity mediated by TRPV1 and TRPA1 in patients with chronic refractory cough. Respir Res 2019; 20: 112 .

29 Zhang X, Chen J, Faltynek CR, et al. Transient receptor potential A1 mediates an osmotically activated ion channel. Eur J Neurosci 2008; 27: 605-611.

30 Juszczak K, Ziomber A, Thor PJ. Effect of partial and complete blockade of vanilloid (TRPV1-6) and ankyrin (TRPA1) transient receptor potential ion channels on urinary bladder motor activity in an experimental hyperosmolar overactive bladder rat model. J Physiol Pharmacol 2011; 62: 321-326.

31 Kumar H, Lee S, Kim K, et al. TRPV4: a sensor for homeostasis and pathological events in the CNS. Mol Neurobiol 2018; 55: 8695-8708.

32 Bonvini SJ, Birrell MA, Grace MS, et al. Transient receptor potential cation channel, subfamily V, member 4 and airway sensory afferent activation: role of adenosine triphosphate. J Allergy Clin Immunol 2016; 138: 249-261. e12.

33 Burnstock G. Discovery of purinergic signalling, the initial resistance and current explosion of interest. $\mathrm{Br}$ Pharmacol 2012; 167: 238-255.

34 Eldred JA, Sanderson J, Wormstone M, et al. Stress-induced ATP release from and growth modulation of human lens and retinal pigment epithelial cells. Biochem Soc Trans 2003; 31: 1213-1215.

35 Guzman-Aranguez A, de Lara P, María J, et al. Hyperosmotic stress induces ATP release and changes in P2X7 receptor levels in human corneal and conjunctival epithelial cells. Purinergic Signal 2017; 13: 249-258.

36 Undem BJ, Carr MJ, Kollarik M. Physiology and plasticity of putative cough fibres in the Guinea pig. Pulm Pharmacol Ther 2002; 15: 193-198.

37 Pedersen SF, Kapus A, Hoffmann EK. Osmosensory mechanisms in cellular and systemic volume regulation. J Am Soc Nephrol 2011; 22: 1587-1597.

38 Eschenbacher WL, Boushey HA, Sheppard D. Alteration in osmolarity of inhaled aerosols cause bronchoconstriction and cough, but absence of a permeant anion causes cough alone. Am Rev Respir Dis 1984; 129: 211-215.

39 Nichol G, Nix A, Barnes PJ, et al. Prostaglandin F2 alpha enhancement of capsaicin induced cough in man modulation by beta 2 adrenergic and anticholinergic drugs. Thorax 1990; 45: 694-698.

40 Smith CA, Adamson DL, Choudry NB, et al. The effect of altering airway tone on the sensitivity of the cough reflex in normal volunteers. Eur Respir J 1991; 4: 1078-1079.

41 Fujimura M, Sakamoto S, Kamio Y, et al. Effects of methacholine induced bronchoconstriction and procaterol induced bronchodilation on cough receptor sensitivity to inhaled capsaicin and tartaric acid. Thorax 1992; 47: 441-445.

42 Fujimura M, Sakamoto S, Kamio Y, et al. Effect of inhaled procaterol on cough receptor sensitivity to capsaicin in patients with asthma or chronic bronchitis and in normal subjects. Thorax 1993; 48: 615-618.

43 Freund-Michel VC, Birrell MA, Giembycz MA, et al. Beta(2)-agonists block tussive responses in guinea pigs via an atypical cAMP-dependent pathway. Eur Respir J 2010; 35: 647-654.

44 Anderson SD, Brannan JD. Methods for "indirect" challenge tests including exercise, eucapnic voluntary hyperpnea, and hypertonic aerosols. Clin Rev Allergy Immunol 2003; 24: 27-54.

45 Johansson E, Ternesten-Hasséus E, Gustafsson P, et al. Small and large airway reactions to osmotic stimuli in asthma and chronic idiopathic cough. Pulm Pharmacol Ther 2018; 49: 112-118.

46 Koskela HO, Kontra KM, Purokivi MK, et al. Hypertonicity of the challenge solution may increase the diagnostic accuracy of histamine challenge. Respir Med 2005; 99: 726-734.

47 Hallstrand TS, Leuppi JD, Joos G, et al. ERS technical standard on bronchial challenge testing: pathophysiology and methodology of indirect airway challenge testing. Eur Respir J 2018; 52: 1801033.

48 Nurmi HM, Lätti AM, Brannan JD, et al. Comparison of mannitol and citric acid cough provocation tests. Respir Med 2019; 158: 14-20.

49 Koskela HO, Lake C, Wong K, et al. Cough sensitivity to mannitol inhalation challenge identifies subjects with chronic cough. Eur Respir J 2018; 51: 1800294.

50 Cho YS, Park SY, Lee C-, et al. Enhanced cough response to hyperpnea with cold air challenge in chronic cough patients showing increased cough sensitivity to inhaled capsaicin. Allergy 2003; 58: 486-491.

51 Banner AS, Chausow A, Green J. The tussive effect of hyperpnea with cold air. Am Rev Respir Dis 1985; 131: 362-367.

52 Koskela HO, Purokivi MK, Tukiainen RM. Simultaneous versus video counting of coughs in hypertonic cough challenges. Cough 2008; 4: 8-8.

53 Fujimura M, Sakamoto S, Kamio Y, et al. Sex difference in the inhaled tartaric acid cough threshold in non-atopic healthy subjects. Thorax 1990; 45: 633-634.

54 Fujimura M, Kasahara K, Kamio Y, et al. Female gender as a determinant of cough threshold to inhaled capsaicin. Eur Respir J 1996; 9: 1624-1626.

55 Kastelik JA, Thompson RH, Aziz I, et al. Sex-related differences in cough reflex sensitivity in patients with chronic cough. Am J Respir Crit Care Med 2002; 166: 961-964.

56 Song W, Kim J, Jo E, et al. Capsaicin cough sensitivity is related to the older female predominant feature in chronic cough patients. Allergy Asthma Immunol Res 2014; 6: 401-408.

57 Lai K, Long L, Yi F, et al. Age and sex distribution of Chinese chronic cough patients and their relationship with capsaicin cough sensitivity. Allergy Asthma Immunol Res 2019; 11: 871-884.

58 Satia I, Tsamandouras N, Holt K, et al. Capsaicin-evoked cough responses in asthmatic patients: Evidence for airway neuronal dysfunction. J Allergy Clin Immunol 2017; 139: 771-779. 
Singapuri A, McKenna S, Brightling CE. The utility of the mannitol challenge in the assessment of chronic cough: a pilot study. Cough 2008; 4: 10 .

60 Anderson SD. 'Indirect' challenges from science to clinical practice. Eur Clin Respir J 2016; 3: 31096.

61 Brannan JD, Anderson SD, Perry CP, et al. The safety and efficacy of inhaled dry powder mannitol as a bronchial provocation test for airway hyperresponsiveness: a phase 3 comparison study with hypertonic (4.5\%) saline. Respir Res 2005; 6: 144.

62 Purokivi M, Koskela HO, Koistinen T, et al. Utility of cough response during hypertonic histamine challenge in diagnosing asthma. Respir Med 2008; 102: 1379-1384.

63 Koskela HO, Purokivi MK. Capability of hypertonic saline cough provocation test to predict the response to inhaled corticosteroids in chronic cough: a prospective, open-label study. Cough 2013; 9: 15-15.

64 Bickerman HA, Barach AL. The experimental production of cough in human subjects induced by citric acid aerosols; preliminary studies on the evaluation of antitussive agents. Am J Med Sci 1954; 228: 156-163.

65 Pounsford JC, Birch MJ, Saunders KB. Effect of bronchodilators on the cough response to inhaled citric acid in normal and asthmatic subjects. Thorax 1985; 40: 662-667.

66 Fujimura M, Sakamoto S, Kamio Y, et al. Cough receptor sensitivity and bronchial responsiveness in normal and asthmatic subjects. Eur Respir J 1992; 5: 291-295.

67 Chang AB, Phelan PD, Sawyer SM, et al. Cough sensitivity in children with asthma, recurrent cough, and cystic fibrosis. Arch Dis Child 1997; 77: 331-334.

68 Schmidt D, Jörres RA, Magnussen H. Citric acid-induced cough thresholds in normal subjects, patients with bronchial asthma, and smokers. Eur J Med Res 1997; 2: 384-388.

69 Fujimura M, Kamio Y, Hashimoto T, et al. Airway cough sensitivity to inhaled capsaicin and bronchial responsiveness to methacholine in asthmatic and bronchitic subjects. Respirology 1998; 3: 267-272.

70 Millqvist E, Bende M, Löwhagen O. Sensory hyperreactivity: a possible mechanism underlying cough and asthma-like symptoms. Allergy 1998; 53: 1208-1212.

71 Di Franco A, Dente FL, Giannini D, et al. Effects of inhaled corticosteroids on cough threshold in patients with bronchial asthma. Pulm Pharmacol Ther 2001; 14: 35-40.

72 Prudon B, Birring SS, Vara DD, et al. Cough and glottic-stop reflex sensitivity in health and disease. Chest 2005 127: 550-557.

73 Hilton EC, Baverel PG, Woodcock A, et al. Pharmacodynamic modeling of cough responses to capsaicin inhalation calls into question the utility of the C5 end point. J Allergy Clin Immunol 2013; 132: 847-855.

74 Johansson E, Gustafsson P, Millqvist E, et al. Small and large airways reactions to inhaled capsaicin in patients with chronic idiopathic cough, or asthma and in healthy control subjects. Exp Lung Res 2019; 45: 55-64.

75 Doherty MJ, Mister R, Pearson MG, et al. Capsaicin responsiveness and cough in asthma and chronic obstructive pulmonary disease. Thorax 2000; 55: 643-649.

76 Dicpinigaitis PV. Capsaicin responsiveness in asthma and COPD. Thorax 2001; 56: 162.

77 Mishra V, Banga J, Silveyra P. Oxidative stress and cellular pathways of asthma and inflammation: Therapeutic strategies and pharmacological targets. Pharmacol Ther 2018; 181: 169-182.

78 Eggleston PA, Kagey-Sobotka A, Schleimer RP, et al. Interaction between hyperosmolar and IgE-mediated histamine release from basophils and mast cells. Am Rev Respir Dis 1984; 130: 86-91.

79 Eggleston PA, Kagey-Sobotka A, Lichtenstein LM. A comparison of the osmotic activation of basophils and human lung mast cells. Am Rev Respir Dis 1987; 135: 1043-1048.

80 Zhang T, Finn DF, Barlow JW, et al. Mast cell stabilisers. Eur J Pharmacol 2016; 778: 158-168.

81 Wang J, Kollarik M, Ru F, et al. Distinct and common expression of receptors for inflammatory mediators in vagal nodose versus jugular capsaicin-sensitive/TRPV1-positive neurons detected by low input RNA sequencing PLoS One 2017; 12: e0185985.

82 Maher SA, Birrell MA, Adcock JJ, et al. Prostaglandin D2 and the role of the DP1, DP2 and TP receptors in the control of airway reflex events. Eur Respir J 2015; 45: 1108-1118.

83 Johnson M. Effects of beta2-agonists on resident and infiltrating inflammatory cells. J Allergy Clin Immunol 2002; 110: 282

84 Lin A, Athukorala A, Gleich GJ, et al. Cough responses to inhaled irritants are enhanced by eosinophil major basic protein in awake mice. Am J Physiol Regul Integr Comp Physiol 2019; 317: R93-R97.

85 Koskela HO, Purokivi MK, Kokkarinen J. Stepping down from combination asthma therapy: The predictors of outcome. Respir Med 2016; 117: 109-115.

86 Taylor-Clark TE. Oxidative stress as activators of sensory nerves for cough. Pulm Pharmacol Ther 2015; 35: 94-99.

87 Taylor-Clark TE, Undem BJ. Sensing pulmonary oxidative stress by lung vagal afferents. Respir Physiol Neurobiol 2011; 178: 406-413.

88 Koskela HO, Purokivi MK. Airway oxidative stress in chronic cough. Cough 2013; 9: 26-26.

89 Koskela HO, Purokivi MK, Nieminen RM, et al. Asthmatic cough and airway oxidative stress. Respir Physiol Neurobiol 2012; 181: 346-350

90 Purokivi M, Koskela H, Kontra K. Determinants of asthma control and quality of life in stable asthma: evaluation of two new cough provocation tests. Clin Respir J 2013; 7: 253-260.

91 Purokivi M, Koskela H, Koistinen T, et al. Assessment of inhaled corticosteroid treatment response in asthma using hypertonic histamine challenge-induced cough. Clin Respir J 2010; 4: 67-73.

92 Koskela HO, Latti AM, Purokivi MK. Long-term prognosis of chronic cough: a prospective, observational cohort study. BMC Pulm Med 2017; 17: 146.

93 Leuppi JD, Tandjung R, Anderson SD, et al. Prediction of treatment-response to inhaled corticosteroids by mannitol-challenge test in COPD. A proof of concept. Pulm Pharmacol Ther 2005; 18: 83-88.

94 Scherr A, Schafroth Török S, Jochmann A, et al. Response to add-on inhaled corticosteroids in COPD based on airway hyperresponsiveness to mannitol. Chest 2012; 142: 919-926.

95 Leuppi JD, Salome CM, Jenkins CR, et al. Predictive markers of asthma exacerbation during stepwise dose reduction of inhaled corticosteroids. Am J Respir Crit Care Med 2001; 163: 406-412. 